\title{
Erythroid Colonies Derived from Fetal Blood Display Different Growth Patterns from those Derived from Adult Marrow
}

\author{
SUZANNE T. HOLBROOK, ROBERT D. CHRISTENSEN, AND GERALD ROTHSTEIN
}

Division of Human Development and Aging, University of Utah School of Medicine, Salt Lake City, Utah 84037

\begin{abstract}
Fetal blood may be useful for the study of hematopoietic development in humans. However, the methods used to study blood cell colonies in adults may not be optimal for the study of colonies derived from fetal blood. Using cord blood from six healthy term pregnancies and marrow from six healthy adult volunteers, we compared the chronology of emergence, morphology, and differentiation of progenitor cell colonies from the two sources. In cultures of adult marrow, erythroid colony-forming unit colonies reached maximal concentrations after $8.5 \pm 0.3$ days of culture (mean \pm SEM), but erythroid colonyforming unit colonies derived from fetal blood reached maximal concentrations sooner, after $6.5 \pm 0.2$ days $(p<$ 0.01). Single-centered-erythroid burst-forming unit colonies from adult marrow (45 $\pm 5 / 10^{5}$ light-density, "accessory-cell"-depleted cells) reached a peak at 14 days, but from cord blood they were significantly greater at 9 days $\left(200 \pm 15 / 10^{5}\right.$ cells) than at 14 days. When studying fetal blood erythroid colony-forming unit and "mature-erythroid burst-forming unit," colonies should be enumerated earlier than when studying adult marrow-derived progenitors. Otherwise, the concentrations of these progenitors will be significantly underestimated. (Pediatr Res 24: 605-608, 1988)
\end{abstract}

Abbreviations
CFU-E, erythroid colony-forming unit
BFU-E, erythroid burst-forming unit
CFU-GM, granulocyte-macrophage colony-forming unit
CFU-Mix, colony-forming units producing clones of eryth-
rocytic, granulocytic, and or megakaryocytic cells

Fetal blood has been used to investigate aspects of developmental hematopoiesis in humans, and generally, investigators have adopted the methods for progenitor cell quantification previously developed for the study of adult marrow (1-8). However, the cell-cycle characteristics of fetal progenitors suggest that the growth of their colonies in vitro might differ in important ways from progenitors of adult marrow $(7,8)$. To assume that the approaches for evaluating fetal blood and adult marrowderived progenitors should be identical may lead to errors. Therefore, we conducted studies of the chronology of colony development and the morphologic constituents of colonies derived from marrow aspirates from healthy adult volunteers and cord

Received March 28, 1988; accepted July 13, 1988.

Correspondence Dr. Robert D. Christensen, Division of Human Development and Aging University of Utah School of Medicine, 50 North Medical Drive, Salt Lake City, Utah 84132 .

Supported by Grant HD-22083 from the National Institutes of Health. blood from healthy term pregnancies. We cultured both lightdensity cells and light-density cells which had been depleted of "accessory cells" $(9,10)$. The plates were examined serially, with mapping of all colonies. All nonoverlapping colonies on replicate plates were characterized morphologically and then transferred to coverslips for cytologic identification. In this way we established the time in culture required for maximal formation of each variety of hematopoietic progenitor cell colony, and compared the accuracy of identifying, in situ, cord blood-derived compared with marrow-derived colonies.

\section{MATERIALS AND METHODS}

Cord blood and bone marrow samples. Blood from the umbilical vein (10-30 ml) was obtained after the placental delivery of six healthy term pregnancies. Marrow aspirations were obtained from six healthy adult volunteers. All samples were anticoagulated with $10-30 \mathrm{U} / \mathrm{ml}$ of preservative-free heparin (Panheparin, Abbott Laboratories, N. Chicago, IL) and processed immediately. The specimens were obtained in accordance with protocols approved by the University of Utah Institutional Review Board and informed consent was obtained from all volunteers.

Culture conditions. For CFU-E determinations, light-density cells $(<1.077$ specific gravity, Ficoll-Hypaque, Pharmacia, Piscataway, $\mathrm{NJ}$ ) were cultured in concentrations of $9-14 \times 10^{4}$ cells/ $\mathrm{ml}$, in $\alpha$-minimal essential medium (Flow General Inc., McLean, VA) with $1.3 \%$ methylcellulose (Sigma Diagnostics, St. Louis, MO), $30 \%$ fetal calf serum (Sigma), $10 \%$ bovine serum albumin (Sigma), $0.25 \mathrm{U}$ human recombinant erythropoietin/ml (Amgen, Thousand Oaks, CA), and $5 \times 10^{-5} \mathrm{M} \beta$-mercaptoethanol (Eastman Kodak Co., Rochester, NY). Penicillin and streptomycin were also added. Four replicate cultures, each containing $1 \mathrm{ml}$, were incubated in plastic $10 \times 35 \mathrm{~mm}$ tissue culture dishes (Becton Dickinson and Co, Oxnard, CA) at $37^{\circ} \mathrm{C}$ in a high humidity $7 \% \mathrm{CO}_{2}$ environment.

For determination of other colony types, cells were cultured in the presence of $1.0 \mathrm{U} / \mathrm{ml}$ recombinant human erythropoietin and, in addition to the constituents listed above, 5\% phytohemagglutinin-stimulated placental-conditioned medium. The medium was produced from freshly delivered placentas of healthy term pregnancies using methods similar to those described by Burgess et al. (12), but $1 \%$ phytohemagglutinin was added to the incubates (13). In cultures of cord blood and adult marrow, $5 \%$ phytohemagglutinin-stimulated, placental-conditioned media resulted in maximal colony formation. In these cultures, concentrations of $2-5 \times 10^{4}$ cells $/ \mathrm{ml}$ were used when adult marrow was studied, and 1-2 $\times 10^{4}$ cells $/ \mathrm{ml}$ were used when cord blood was studied.

To deplete fetal and adult samples of "accessory cells," lightdensity cells not adherent to plastic were incubated for 20 min in the presence of anti-human Leu-1 $(240 \mu \mathrm{l})$, anti-Leu-5b (96 $\mu \mathrm{l})$, and anti-Leu M5 (120 $\mu \mathrm{l})$ (Becton-Dickinson). This mixture 
was then suspended in phosphate-buffered saline containing $5 \%$ fetal calf serum (Sigma) and layered on $100 \times 15 \mathrm{~mm}$ plastic dishes (Becton-Dickinson) which had previously been coated with goat anti-mouse IgG (Zymed Laboratories, San Francisco, $\mathrm{CA})$ and incubated for $70 \mathrm{~min}$ at $4^{\circ} \mathrm{C}(10,11,14)$.

Scoring of cultures. Beginning on the first day of culture, plates were examined serially at $50 \times$ magnification, using an inverted microscope. Mapping of all clusters containing 8 or more cells was accomplished at each examination. To compare our ability to determine the cellular make-up of cord blood-derived versus adult marrow-derived colonies, we first classified all colonies as belonging in one of four morphologic categories, and then lifted all nonoverlapping colonies and transferred them to glass coverslips for staining and cell differential counts using oil-immersion microscopy at $1000 \times$ magnification. The four morphologic categories used were intended to identify CFU-E, BFU-E, CFUGM, and CFU-Mix. Putative CFU-E colonies were identified in situ as those composed of very tightly clustered cells developing in plates to which erythropoietin $(0.25 \mathrm{U} / \mathrm{ml})$ was the only added stimulator. BFU-E colonies were single or multiply centered red colonies composed of very tightly clustered cells, developing in plates to which erythropoietin $(1.0 \mathrm{U} / \mathrm{ml})$ and maximal stimulatory concentrations of conditioned medium had been added. Colonies were classified as having been derived from CFU-GM if they contained no red elements and the cells were loosely grouped, with either dense centers or no focal center. CFU-Mix contained tightly clustered red segments plus loosely grouped cells.

Statistical comparisons were made using Student's $t$ test, or, where identified, by Fisher's exact test.

\section{RESULTS}

$C F U$-E colonies. For each sample, quadruplicate culture plates were examined daily for 9-10 days and then every other day until day 14. The chronologic appearance of tightly clustered groups of $\geq 16$ cells is shown in Figure 1. In cultures of cord blood origin, CFU-E colonies reached maximal concentrations more rapidly (after $6.5 \pm 0.2$ days) than did similar appearing colonies cultured from adult marrow (after $8.5 \pm 0.3$ days, $p<$ $0.05)$. In five of the six cultures from adults maximal colony

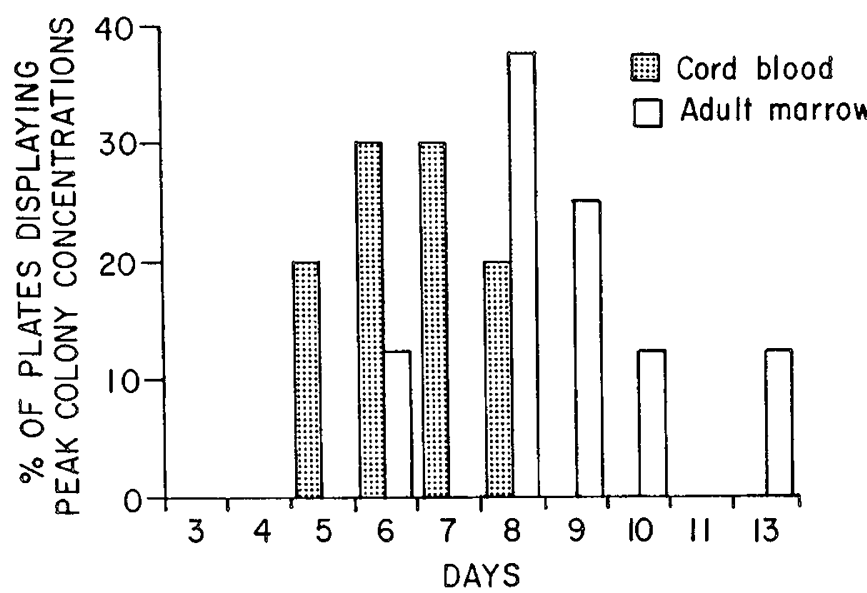

Fig. 1. Time in culture for maximal appearance of CFU-E colonies. The percentage of culture plates achieving maximal concentrations of CFU-E colonies on various days of culture is depicted by the bars. The shaded bars signify colonies derived from six term cord blood specimens and the open bars represent colonies from six bone marrow specimens from healthy adults. This variety of colony of cord blood origin achieved maximal expression at $6.5 \pm 0.2$ days and of adult marrow origin at 8.5 \pm 0.3 days $(p<0.05)$ formation occurred on or after the 8th day, but none of the cord blood specimens displayed maximal colony formation beyond the 8 th day. If colonies from cord blood had been scored on day $9\left(50.7 \pm 10.2\right.$ colonies $/ 10^{5}$ plated cells) rather than on day 6 $\left(99.4 \pm 12.9\right.$ colonies $\left./ 10^{5}\right)$, a significant underestimate would have occurred $(p=0.01)$.

Depletion of accessory cells did not affect the chronology of appearance of CFU-E colonies, but reduced the concentration of the only other variety of colony that appeared in these plates: colonies composed of loosely arranged cells. Upon Wright's staining of cover slip smears, such loose colonies were composed exclusively of macrophages.

Single-centered BFU-E colonies. Figure 2 shows the appearance of single-centered BFU-E colonies. These colonies reached maximal concentrations at 14 days in adult marrow cultures (upper panel), but in cultures of cord blood (lower panel), concentrations were greater on the 9th than the 14 th $(p<0.05)$ or 17 th day $(p<0.01)$. If these colonies from cord blood had been counted on day 14 rather than day 9 , a significant underestimate ( $140 \pm 25$ colonies $/ 10^{5}$ light-density, accessory-cell-depleted cells, versus $\left.200 \pm 15 / 10^{5}\right)$ would have occurred $(p<0.05)$.

Figure 2 shows only pure normoblast colonies. Upon examination of stained cells, not all of the colonies that had been tentatively classified in situ as single-centered-BFU-E colonies were composed exclusively of normoblasts. Colonies of tightly clustered cells that contained fewer than $30-40$ cells, not clearly displaying a red color, often did not contain normoblasts. This was particularly true of colonies examined at 9 days. Specifically, in cultures from adult marrow examined at 9 days, only five of 23 single-centered colonies of tightly clustered cells were composed exclusively of normoblasts. The majority of such colonies

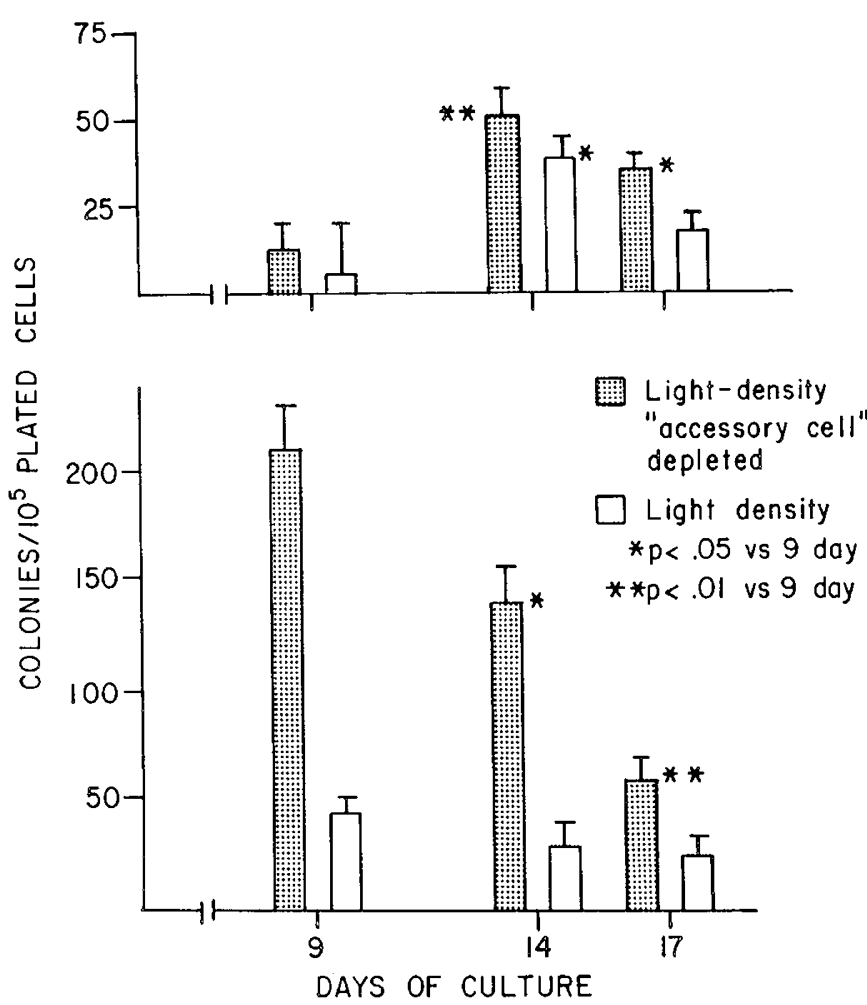

Fig. 2. Single-centered BFU-E colonies. The upper panel depicts colonies grown from six adult marrow samples and the lower panel from six cord blood samples. The bar represents the mean value and the bracket represents the SEM. The open bars represent colonies grown from the light-density cell fraction, and the shaded bars represent colonies grown from light-density cells subjected to depletion of accessory-cells. 
(10 of 23) was composed of immature-appearing macrophages, and eight of 23 such colonies contained mixtures of normoblasts and immature-appearing macrophages. In 16 single-centered, tightly clustered colonies of cord blood origin, examined at 9 days, six exclusively contained normoblasts, eight contained only macrophages, and two contained macrophages plus normoblasts. When colonies of this description were examined at 14 days of culture, 12 of 14 colonies from cord blood and nine of 11 from adult marrow contained only normoblasts.

Multiple-centered BFU-E, CFU-GM, and CFU-MIX colonies. The time of maximal appearance of multiple-centered BFU-E colonies (14 days) was similar for adult marrow and cord blood. However, the concentration was more than 10 -fold higher in cord blood ( $160 \pm 18$ colonies $/ 10^{5}$ light-density, accessory-celldepleted cells) than in adult marrow $\left(10 \pm 2 / 10^{5}, p<0.01\right)$. Many colonies identified in situ as multiple-centered BFU-E contained mixtures of macrophages and normoblasts. For instance, of 69 putative multiple-centered BFU-E colonies of cord blood origin, $50(72 \%)$ contained only normoblasts, but 19 contained normoblasts and macrophages. Of 28 colonies of adult marrow origin identified in situ as multiple-centered BFU-E, 12 (43\%) contained only normoblasts $(p<0.01$ versus cord blood, Fisher exact). When scored after only 9 days, all colonies of adult marrow origin identified in situ as multiple-centered BFU-E contained mixtures of normoblasts and macrophages.

Fourteen days of culture also appeared optimal for enumeration of CFU-GM colonies, if derived from adult marrow or from cord blood. However, their concentration in cord blood $(290 \pm$ 20 colonies on day $14 / 10^{5}$ light-density, accessory-cell-depleted cells) greatly exceeded the concentration in adult marrow (120 $\pm 8 / 10^{5}$ cells, $p<0.01$ ). Of 80 putative CFU-GM colonies lifted from plates of cord blood origin, 74 (93\%) were composed only of granulocytes and macrophages, the remaining six colonies contained mixtures of nonhemoglobinized normoblasts and granulocytes. Of 63 colonies lifted from plates of adult marrow origin, $55(87 \%)$ contained only granulocytes and macrophages, the remaining eight contained granulocytes, macrophages, and normoblasts.

The maximal appearance of CFU-Mix colonies derived from adult marrow and cord blood was also at 14 days. However, cord blood contained a greater concentration $(96 \pm 21$ colonies at 14 days $/ 10^{5}$ light-density accessory-cell-depleted cells plated) than did adult marrow $\left(22 \pm 13 / 10^{5}, p<0.01\right)$. Of 39 colonies of cord blood origin putatively identified in situ as having been derived from CFU-Mix, $30(77 \%)$ were confirmed as such. Of the remaining nine colonies, five contained only normoblasts, and four contained only granulocytes and macrophages. Of 27 colonies of adult marrow origin identified in situ as having been derived from CFU-Mix, $18(67 \%)$ were confirmed as such. The remaining nine colonies contained only granulocytes plus macrophages.

\section{DISCUSSION}

Although present in very low concentrations in venous blood of adults, CFU-E $(2,4,6)$, BFU-E $(2,4,6)$, CFU-GM $(1,3,7)$, and multipotent progenitors $(5,8)$ comprise a substantial proportion of the light-density cell population in fetal blood. Blood from prematurely delivered neonates appears to have even higher concentrations $(7,8)$. Sequential study of the intrauterine development of these progenitors and their response to hematopoietic regulators will be possible using intrauterine cordocentesis during gestation. If accurately performed, such studies may provide insights into developmental hematopoiesis. However, it has not been clear if the methods generally used for enumeration of hematopoietic progenitors (developed for study of adult marrow), are suitable for the study of progenitors from cord blood. From the present studies, we conclude that in the present culture conditions, CFU-E and single-centered BFU-E of term gestation cord-blood origin form colonies in vitro significantly sooner than do those of adult marrow origin. These colonies decline in number after the peak of their appearance. Therefore, quantification of CFU-E colonies from cord blood on day 8 or 9 rather than day 6 or 7 , or quantification of single-centered BFU-E colonies on day 14 rather than day 9 , would significantly underestimate the cord blood's content of those progenitors.

A possible explanation for the more rapid in vitro maturation of CFU-E and mature-BFU-E is a shortened cell-cycle time of these cord blood-derived progenitors. Gregory and Eaves (15) have suggested that the more rapid appearance of murine CFU$\mathrm{E}$ colonies in culture, compared to human CFU-E colonies, is due to a shorter cell cycle time of murine red cell precursors (16, 17). Thymidine suicide rates for human adult marrow-derived CFU-E of about $60 \%$, and for mature-BFU-E of $40-50 \%$ have been observed by Eaves et al. (18). We have reported similar values in adult marrow (19), but have observed even higher suicide rates, $70-80 \%$ for CFU-E and $50-60 \%$ for mature-BFU$\mathrm{E}$, in cord blood samples (19).

In other portions of the study, we evaluated the accuracy of identifying colony differentiation in situ. The most frequent source of potential confusion in colony-type identification was that, when examined after only 9 days of culture, small singlecentered normoblast-containing colonies could not be reliably distinguished from colonies composed of tightly clustered immature macrophages, or from colonies composed of mixtures of macrophages and normoblasts. This was the case in fetal and adult colonies. In addition, we noted, as have others $(13,18)$, that colonies identified in situ as multiple-centered BFU-E often contained macrophages plus normoblasts. However, BFU-E colonies from cord blood origin were less likely to contain macrophages than were those of adult marrow origin.

We conclude that, under the present culture conditions, the early erythroid progenitors from fetal blood at term do not display the same chronologic pattern of colony formation as do those from adult marrow. These studies serve as a reminder that the proper methodology for an experimental system must be characterized anew when different cell types are studied. For instance, as cordocentesis samples obtained very early during gestation are cultured, additional investigation will be required to define the optimal conditions for growth and enumeration of those progenitors.

\section{REFERENCES}

1. Knudtzon S 1974 In vitro growth of granulocytic colonies from circulating cells in human cord blood. Blood 43:375-361

2. Hassan MW, Lutton JD, Levere RD, Reider RF, Cederquist LL 1979 In vitro culture of erythroid colonies from human fetal liver and umbilical cord blood. Br J Haematol 41:477-484

3. Prindull G, Gabriel M, Prindull B 1981 Circulating myelopoietic stem cells (CFUc). Blut 43:109-111

4. Issaragrisil S 1983 Correlation between hematopoietic progenitors and erythroblasts in cord blood. Am J Clin Pathol 80:865-867

5. Hann IM, Bodger MP, Hoffbrand AV 1983 Development of pluripotent hemopoietic progenitor cells in the human fetus. Blood 62:118-123

6. Shekter-Levin S, Amato D, Axelrad AA 1984 The proliferative rate of early erythropoietic progenitor cells (BFU-E) in human umbilical cord blood. Exp Hematol 12:650-654

7. Christensen RD, Harper TE, Rothstein G 1986 Granulocyte-macrophage progenitor cells (CFU-GM) in term and preterm neonates. $J$ Pediatr 109:1047-1051

8. Christensen RD 1987 Circulating pluripotent hematopoietic progenitor cells in neonates. J Pediatr 110:622-625

9. Bagby GC, McCall E, Layman DL 1983 Regulation of colony stimulating activity production. Interactions of fibroblasts, mononuclear phagocytes and lactoferrin. J Clin Invest $71: 340-344$

10. Emerson SG, Sieff CA, Wang EA, Wong GG, Clark SC, Nathan DG 1985 Purification of hemopoietic progenitors and demonstration of recombinant multipotential colony stimulating activity. J Clin Invest 76:1286-1290

11. Sieff CA, Emerson SG, Mufson A, Gesner TG, Nathan DG 1986 Dependence of highly enriched human bone marrow progenitors on hemopoietic growth factors and their response to recombinant erythropoietin. J Clin Invest $77: 74-81$ 
12. Burgess AW, Wilson EMA, Metcalf D 1977 Stimulation by human placental conditioned medium of hemopoietic colony formation by human marrow cells. Blood 49:573-583

13. Ogawa M, Leary AG 1984 Erythroid progenitors. In: Golde DW (ed) Hematopoiesis. Churchill Livingston, New York, pp 126-127

14. Wysocki LJ, Sato VL 1978 "Panning" for lymphocytes: a method for cell selection. Proc Natl Acad Sci USA 75:2844-2848

15. Gregory CJ, Eaves AC 1977 Human marrow cells capable of erythropoietic differentiation in vitro. Definition of three erythroid colony responses. Blood 49:855-864

16. Killmann SA, Cronkite EP, Fliedner TM, Bond VP 1964 Mitotic indices of human bone marrow cells. III. Duration of some phases of erythrocytic and granulocytic proliferation computed from mitotic indices. Blood 24:267280

17. Gregory CJ 1976 Erythropoietin sensitivity as a differentiation marker in the hematopoietic system: studies of three erythropoietic colony responses in culture. J Cell Physiol 89:289-301

18. Eaves CJ, Humphries RK, Eaves AC 1979 Cellular and Molecular Regulation of Hemoglobin Switching. Grune and Stratton, New York

19. Christensen RD, Leckman S, Saffle JR, Rothstein G 1988 Haematopoietic progenitor cells in an infant who developed pancytopenia following an extensive burn. Burns Incl Therm Inj 14:101-106 